\title{
Enterprise Resource Planning (ERP) Systems: Emergence, Importance and Challenges
}

\author{
Dr. Adnan Mustafa AIBar \\ Department of Information Systems \\ Faculty of Computing \& Information Technology \\ King Abdulaziz University, Jeddah, Saudi Arabia \\ Email: ambar@kau.edu.sa \\ Mashael A. Hddas \\ Department of Information Systems \\ Faculty of Computing \& Information Technology \\ King Abdulaziz University, Jeddah, Saudi Arabia \\ Email:profmashael123@gmail.com \\ Md. Rakibul Hoque* \\ Department of Management Information Systems \\ Faculty of Business Studies \\ University of Dhaka, Dhaka-1000, Bangladesh \\ Email:rakibul@du.ac.bd
}

\begin{abstract}
The Enterprise Resource Planning (ERP) has dawned as a tool to facilitate the flow of information and allow information sharing among different business partners. It appears as a response to the inappropriateness of the traditional systems which become outdated as a result of the change in business needs and the development of software programs. The use of ERP software has become more common in a lot of businesses nowadays. It appears as a complex and comprehensive software through which organizations can control and integrate all the business functions and processes in an extensive and innovative technique. This paper is dedicated to discuss enterprise resource planning, its emergence, implementation, importance of using it within organizations and the different challenges related to its implementation. Finally, discussion will be identified to review the most important issues and provide suggestions on the practical level to make effective use of this system.
\end{abstract}

Key words: ERP, Software systems.

\section{Introduction}

The complexity of the business and work environment nowadays and the changing nature of market requirements have led to looking for systems that could improve organizations competitiveness, achieve cost effectiveness and cope with the logistic needs. The Enterprise Resource Planning (ERP) has emerged as a technique to balance between demand and supply, reinforce business productivity and promote the quality of processes. ${ }^{1}$ ERP is a software that is dedicated to manage all business processes through using an integrated and comprehensive applications to manage different tasks and operations in different fields such as planning, manufacturing, sales, marketing, human resources, purchasing, etc and unified them in a single

*Corresponding author: Cell:+8801912928171.

Email: rakibul@du.ac.bd 
platform that lead to effective real changes on the organizational level and increase in the level of revenues. $^{2}$ The emergence of ERP software as a way to integrate the processes and functions of the organization in a unified and advanced technique by sharing a common database in such a way that supports the effective and efficient implementation of different operations within the organization. ${ }^{3}$

There are many factors that prompt the use of ERP in different business organizations among them are the inability of existing system to fulfill organizational needs and provide extensive resources for maintenance and support, the incompatibility of several information systems with the current business systems and the inability of employees to respond easily and quickly to customers or suppliers' inquiries and concerns. ${ }^{4}$

ERP systems contain several configuration options for each business process based on best practices which sometimes force the firm to reengineer its business processes to be compatible with the software package options..$^{5}$ The retrofit of technical infrastructure has succeeded in transforming the way ERP systems work; at first, installing and maintaining an ERP system were expensive and took a relatively long time to get the revenue, after that the implementation and maintenance cost of ERP system was greatly decreased due to technical infrastructure modernization. ${ }^{6}$

According to Chung, ERP systems are able to minimize data replication, control data records, and reduce registration errors. The interdependence and interconnectivity among all processes of ERP systems reduce the time needed to perform the different operational tasks, so the process efficiency can be increased and the speed of performing operations can be doubled. $^{7}$

Also, Umble tried to highlight the strengths that distinguish ERP systems from non-integrated traditional systems; first it provides a unified enterprise view of the business and a scheme of how functions should be performed in different departments. Second, it introduces an enterprise database where all business transactions are saved, processed, evaluated and disclosed. In other words, it provides an accurate methodology which helps mangers and employers to quickly access database and find what they are searching for. ${ }^{8}$

In addition, it can be used as a measure for enterprise development. Once the firm acknowledges ERP benefits, then those potential benefits can be used as a predicator for signifying the extent of attaining goals and objectives to identify whether enterprises have achieved the potential benefits or they need to reorganize and restructure their processes to achieve the expected outcomes from the implementation of these systems. ${ }^{9}$ Jackson proved that the use of ERP systems can be very effective in day-to-day HR administrative tasks through creating integration in its all processes, this integration results in improving productivity, reduced cycle times, and availability of timely information regarding all tasks within these departments. ${ }^{10}$

Even though, the growing use of ERP system and the increased importance of such systems to the business and work environment, some enterprises may find certain difficulties related to the complexity of the software whether in its activation or implementation. This issue was stressed in many studies mentioned in the literature, for example Gall identified one of the most prominent obstacles that challenge the effective implementation of such systems within business environments such as the huge complexity of ERP systems. ${ }^{11}$ Researchers stated some considerations must be taken into account while implementing ERP systems within organizations such as operational disruptions within the work environment, network, application and database security, processes interconnection and risk control. $^{12}$

\section{Emergence of ERP}

ERP system can be dated back to standard inventory control packages designed to handle traditional inventory processes without addressing the finance and accounting area. ${ }^{13}$ The late eighties and early nineties has witnessed the emergence of new software systems known as ERP targeting mainly large complex business organizations. This complex, expensive and powerful systems become available for most organizations, it requires nothing but consultants who can install and implement them based on the company's requirements and real needs. ${ }^{14}$

She \& Thuraisingham tried to mention the merits of this technology by emphasizing its role in integrating the core processes within the business chain. One must recognize that the advancement of ERP systems are now experiencing will make it highly integrated, more 
collaborative, web-enabled, and even wirelessdepended. $^{15}$

ERP systems have begun to emerge in the field of resource management in the late $1980 \mathrm{~s}$ and the beginning of 1990s mainly targeted to large business organizations. To run these complex and powerful systems; they require professional consultants to implement them within organizations that have different requirements and needs and as a result, these systems require organizations to reengineer all their business processes to accommodate the software modules. These systems have options to add "add-on" when organizational processes required these options to ensure effective and comprehensive application. ${ }^{16}$

The need for information systems in general and ERP systems in particular emerged from the assumptions that these systems are considered as being pillars for the survival of organizations as they can provide many options facilitating the flow of processes and operations across the organization such as speedy access of information anytime and anywhere and accurate processing of data that can be used in different operations and by different levels from senior management to ordinary employees. Speedy access of data is very helpful especially for the processes of preparing different reports and minimizing errors that used to occur while depending on manual strategies for collecting information. ${ }^{17}$

\section{Importance of ERP}

ERP systems are of great importance for work and business environments today; while looking at different organizations and processes associated with them, we can say that organizations aren't separated entities in which each department works independently of other departments but rather they are integrative processes where all departments work in harmony with each other to achieve the objectives and goals of the whole organizations. Avram stated that among the most important advantages of using ERP in organizations are the integration of different tasks and functionalities and help senior management in decision making processes through providing different alternatives and showing the negative and positive effects linked to them. ${ }^{18}$

ERP software is seen as a strategy that help different organizations to cope with the requirements and needs of the current era that heavily depend on competition among different organizations. Here, Employing information systems represented in ERP software help different organizations to gain competitive advantage and enhance their productivity during changing environments and during times of crises in such a way that encourages their expansion. ${ }^{19}$

Seo showed that the real benefits of using ERP systems in organizations stemmed from the fact that they affect the entire organization including processes, employees and organizational culture, they provide opportunities for enhancing real time capabilities and ensure the smooth communication among all employees and departments within the organization in such a way that emphasize the unity of the organization policies, objectives and visions. ${ }^{20}$ In addition, Zimmerman \& Smedley stated that the use of ERP systems is effective mechanisms that can be used in creating an internal flow of information accessible to everyone within the organization. $^{21}$

Accurate processing of the data and effective use of information are pivotal elements for the success of all types of organizations around the world. By and large, it is observed that using the ERP systems can enhance the efficiency of doing business processes, facilitate organizational learning, broaden workers' skills and capabilities especially in the field of information skills, all these issues have positive effects on the quality of work and as a result on the overall performance of the organization and its market shares locally and globally. ${ }^{22}$

\section{Implementation of ERP}

ERP system can run on different hardware and network configurations such as Software as a Service "SaaS", Mac OS, Linux and so on, the operation process can be done through a comprehensive database that help in keeping information from all organization departments accessible for whom it may concern, the database here is used as a central repository for information that allows faster and accurate analysis of data. ${ }^{23}$

It is worthy here to mention that the effective implementation of ERP systems depends on many internal and external factors for example organizational culture, leadership support, clear implementation plan, continuous overview of the budget and available financial resources and employees' internal motivation and openness to change, desire to update the traditional methods of doing work are among the common internal factors that may affect the implementation of ERP 
systems in organizations while the policies and obligations that govern the work environment and be supported by higher authorities are considered among the external ones. ${ }^{24}$

Abdelghaffar investigated the different factors that may affect the implementation of ERP systems in developing countries organizations. The results of the study showed that economic growth, government policies, the type of ICT infrastructure and organizational factors especially the computer culture, management commitment, business process re-engineering and IT maturity level are among the most important factors that may affect the implementation of these systems. ${ }^{19}$

Motwani et al. found that a cautious, bureaucratic implementation process backed with careful change management, and cultural readiness can lead to a successful ERP project implementation. ${ }^{25}$ It is also obvious that ERP implementation depends on four distinct phases such as preparation and training, transition, performance and usefulness, and maintenance. Peslak et al found that two significant phases which directly influenced ERP implementation are preparation and training phase and performance and usefulness phase. $^{26}$

Researcher identified different strategies such as organizational, technical, and people strategies for implementing ERP successfully. Organizational strategies include change management techniques, project management, organizational structure, managerial style, and organizational resources. Technical strategies include technical aspects of ERP installation, adequacy of in-house technical expertise, ERP complexity, and time and cost of implementation. Finally, people strategies include staff and management attitudes, and training. ${ }^{27}$

\section{Challenges of ERP Systems Implementation}

It is also not uncommon that there are many challenges linked to the use of ERP systems in organizations revolved around the financial and technical issues. Grabski et al. identified five major challenges which influences the effective implementation of ERP systems within the organization such as the lack of consistency or harmony between the requirements of ERP system and the real needs of the business processes, the possible loss of control over employees or over processes, the risks related the level of complexity in managing the system, lack of in house skills. Sometimes users and/or employees may feel resistance of this type of systems due to their inability to go in harmony with the requirements of these systems or their desire to adhere to the stereotyped models of performing the roles. $^{28}$

Although stories of success of some organizations that have managed to effectively implement ERP software in managing all their processes can be used as useful guidelines for analyzing varying factors that help in improving the performance of ERP, these stories and experiences can't be used in other organizations because of the differences in the organizational processes, leadership styles and organizational objectives and goals, consequently the results of successful experiences cannot be generalized. $^{29}$

ERP systems are not widely adopted or used in many organizations especially in the developing world. Rajapakse \& Seddon marked some challenges that hinder the effective implementation of ERP in organizations in developing countries. They found that high cost of installing and maintenance and the lack of knowledge regarding how these systems operate are among the most common challenges that impede the implementation of these software systems. ${ }^{30}$

Hong and Kim found that the cost of ERP systems installation and implementation is high, it is very complex and it requires long time to train individuals on how to use it. In addition, it needs professionals to deal with them as they have many features and only professional can identify which features are necessary for the business processes. ${ }^{31}$ The architecture of ERP system may conflict with the business processes of the organization which leads to the inability of achieving strategic goals the organization seek to achieve. Also, installing and implementing these systems may require change in the organizational structure and patterns of doing things; this may cause the ambiguity of the roles performed by employees. ${ }^{32}$

\section{Discussion and Implication}

In the current era, all organizations around the world seek to improve their business processes and adopt many technological solutions in an attempt to enhance their competitive advantages and to be part of the global work environment; these factors provide opportunities to present many different types of enterprise information software packages. ERP systems are special models of information systems aimed at integrating all 
business processes and information flows in one central package with easy to access to all stakeholders. ERP systems have proved themselves to be effective mechanisms to improve productivity, sustain competitive advantage, develop business processes, enhance work performance, increase profitability and revenues and ensure quality in all processes, products and services provided by the organization. ${ }^{33}$

It is recommended that for organizations to have the ability to overcome the different challenges and risks associated with using ERP systems in managing their business processes, some points shall be taken into consideration. For the problem of lack of consistency or harmony between the requirements of ERP system and the real needs of the business processes; organizations should tend to business process reengineering as a mechanism to cope with the new system requirements and maximize the benefits of using it in different organizations depending mainly on redesigning all processes in accordance with the system requirements. ${ }^{34}$ For the problem of lack of control over business processes, it is recommended that organizations must have specialized committees to help mangers and leaders in making sound decisions regarding the flow of processes within the work environment. While the problem of cost is considered among the most common discussed topics in the literature regarding the obstacles of activating ERP systems in organizations; we can say that this problem can be solved if organizations have specialized enough financial resources to fund these systems, specializing financial resources must be done at the early stages of the project (during the planning phase) to ensure that no financial crises will be occurred while conducting the project. It is very useful here to use cost - benefit analysis to estimate the amount of money needed to employ the software in the organization and estimate the probable benefits that may result from employing it.

Regarding the problem of complexity of these systems, it is recommended that organizations may have professional specialists in the field of information technology who have the ability to deal with the technical requirements of these systems and train employees on how to tackle the problems linked to the use of these systems. To effectively do that within the work environment, strong relationships should be established between technical specialists and employees to ensure effective transfer of knowledge and upgrade employees' skills and capabilities in dealing with these complex systems. Here, we should mention that specialists shouldn't only have the technical expertise that enables them to deal with the system, they should also have effective communication skills that enable them to interact with all employees through appropriate language they can understand regarding the nature of the system and the problems that can be associated it.

If employees show some resistance to the new systems, it is recommended to held training sessions, seminars and workshop to help employees identifying the nature of these systems and the different benefits associated with using them within the work environment, consequently they can show positive attitudes towards these systems and become motivated to try to operate them. It is useful to stress the importance of updating the ICT infrastructure of the organization periodically to align with the different expectations and needs of the technological advancement.

\section{Conclusion}

ERP systems have proved themselves to be very efficient systems that can be used by different organizations specialized in different fields and services. Although there are many challenges that could hinder the effective implementation, these challenges can be well managed overcome by taking certain procedures by the management team in order to ensure making full use of these systems in the organizations and achieving the expected benefits from using them. Management and leadership within different organizations must train their teams on employing technology in different activities and processes to facilitate doing work, improve the efficiency of different processes and manage the work place environment more effectively.

\section{Conflict of Interest}

There are no known conflicts of interest. 


\section{References}

1. Robinson, B., \& Wilson, F. (2001). Planning for the market?: Enterprise resource planning systems and the contradictions of capital. ACM SIGMIS Database, 32(4), 2133.

2. Berchet, C., \& Habchi, G. (2005). The implementation and deployment of an ERP system: An industrial case study. Computers in Industry, 56(6), 588-605.

3. Newell, S., Huang, J. C., Galliers, R. D., \& Pan, S. L. (2003). Implementing enterprise resource planning and knowledge management systems in tandem: fostering efficiency and innovation complementarity. Information and Organization, 13(1), 25-52.

4. Chen, I. J. (2001). Planning for ERP systems: analysis and future trend. Business process management journal, 7(5), 374386.

5. Bradley, J. (2004). Enterprise Resource Planning Success: A Management Theory Approach to Critical Success Factors. Doctor of Philosophy, Claremont Graduate University.

6. She, W., \& Thuraisingham, B. (2007). Security for enterprise resource planning systems. Information Systems Security, 16(3), 152-163.

7. Chung, B. (2007). An analysis of success and failure factors for ERP systems in engineering and construction firms. ProQuest.

8. Umble, E. J., Haft, R. R., \& Umble, M. M. (2003). Enterprise resource planning: Implementation procedures and critical success factors. European journal of operational research, 146(2), 241-257.

9. O'Leary, D. E. (2004). Enterprise resource planning (ERP) systems: an empirical analysis of benefits. Journal of Emerging Technologies in Accounting, 1(1), 63-72.

10. Jackson, L. A. (2010). Enterprise resource planning systems: revolutionizing lodging human resources management. Worldwide Hospitality and Tourism Themes, 2(1), 20-29.

11. Gall, M., Grechenig, T., \& Bjerre, M. (2011). Assessing the feasibility of developing a federated erp system. arXiv preprint arXiv:1109.0098.

12. Hunton, J., Wright, A., \& Wright, S. (2001, May). Business and audit risks associated with ERP systems: knowledge differences between information systems audit specialists and financial auditors. In 4th European Conference on Accounting Information Systems (ECAIS), Athens.

13. Shehab, E. M., Sharp, M. W., Supramaniam, L., \& Spedding, T. A. (2004). Enterprise resource planning: An integrative review. Business Process Management Journal, 10(4), 359-386.

14. Rashid, M. A., Hossain, L., \& Patrick, J. D. (2002). The evolution of ERP systems: A historical perspective. Enterprise Resource Planning: Global opportunities \& challenges, 1-16. 15. She, W., \& Thuraisingham, B. (2007). Security for enterprise resource planning systems. Information Systems Security, 16(3), 152-163.

16. Hossain, L., Patrick, J. D., Rashid, M. A., \& Rashid, M. A. (2002). Enterprise resource planning: global opportunities and challenges. IGI Global.

17. Cadili, S., \& Whitley, E. A. (2005). On the interpretative flexibility of hosted ERP systems. The Journal of Strategic Information Systems, 14(2), 167-195.
18. Avram, C. D. (2010). ERP inside Large Organizations. Informatica Economica, 14(4), 196-208.

19. Abdelghaffar, H. (2012). Success Factors for ERP Implementation in Large Organizations: The Case of Egypt. The Electronic Journal of Information Systems in Developing Countries, 52.

20. Seo, G. (2013). Challenges in implementing enterprise resource planning (ERP) system in large organizations: similarities and differences between corporate and university environment (Doctoral dissertation, Massachusetts Institute of Technology).

21. Zimmerman, E., \& Smedley, J. (2006). ERP Implementations-a never ending story?. In Proceedings of the 29th IRIS (p. 12). IRIS.

22. Gupta, M., \& Kohli, A. (2006). Enterprise resource planning systems and its implications for operations function. Technovation, 26(5), 687-696.

23. Suciu, G., Fratu, O., Halunga, S., Cernat, C. G., Poenaru, V., \& Suciu, V. (2011, November). Cloud consulting: ERP and communication application integration in open source cloud systems. In Telecommunications Forum (TELFOR), 2011 19th (pp. 578-581). IEEE.

24. Scott, J. E., \& Vessey, I. (2000). Implementing enterprise resource planning systems: the role of learning from failure. Information systems frontiers, 2(2), 213-232.

25. Motwani, J., Mirchandani, D., Madan, M., \& Gunasekaran, A. (2002). Successful implementation of ERP projects: evidence from two case studies. International Journal of Production Economics, 75(1), 83-96.

26. Peslak, A. R., Subramanian, G. H., \& Clayton, G. E. (2008). The phases of ERP software implementation and maintenance: A model for predicting preferred ERP use. Journal of Computer Information Systems, 48(2), 25.

27. Aladwani, A. M. (2001). Change management strategies for successful ERP implementation. Business Process management journal, 7(3), 266-275.

28. Grabski, S. V., Leech, S. A., \& Lu, B. (2001). Risks and controls in the implementation of ERP systems. The International journal of digital accounting research, 1, 8 .

29. Shad, S. A., Chen, E., \& Azeem, F. M. F. (2012). Performance enhancement factors of ERP projects in a telecom public sector organization of Pakistan: an exploratory study. arXiv preprint arXiv:1207.2862.

30. Rajapakse, J., \& Seddon, P. B. (2005). Why ERP may not be suitable for organizations in developing countries in Asia. Proceedings of PACIS, 1382-1388.

31. Hong, K. K., \& Kim, Y. G. (2002). The critical success factors for ERP implementation: an organizational fit perspective. Information \& Management, 40(1), 25-40.

32. Legare, T. L. (2002). The role of organizational factors in realizing ERP benefits. Information Systems Management, 19(4), 21-42.

33. Bendoly, E., \& Schoenherr, T. (2005). ERP system and implementation-process benefits: implications for B2B eprocurement. International Journal of Operations \& Production Management, 25(4), 304-319.

34. Yeh, J. Y., \& OuYang, Y. C. (2010). How an organization changes in ERP implementation: a Taiwan semiconductor case study. Business Process Management Journal, 16(2), 209-225. 